Protestantismo em Revista é licenciada sob uma Licença Creative Commons.

http://dx.doi.org/10.22351/nepp.v44i1.3318

\title{
Valorização dos Estudos Culturais no Brasil a partir das influências inglesas
}

\author{
Valorization of Cultural Studies in Brazil based on English influences
}

Fábio Teixeira Lima*

Ezequiel de Souza**

\begin{abstract}
Resumo
Este artigo procura apresentar e discutir as influências inglesas com a nova disciplina sobre os estudos culturais para o Brasil, partindo do pressuposto de seus idealizadores, os estudiosos Richard Hoggart, Raymond Williams e E. P. Thompson, com o objetivo de realizar uma análise histórica e reflexiva a respeito da dinâmica cultural e suas correlações com diversas áreas das ciências humanas, relacionadas com a própria existência e convivência do homem, enquanto ser social, dentro do processo de colonização e civilização, essa nova metodologia foi bastante importante para o Brasil, pela valorização dos argumentos dos autores clássicos da historiografia brasileira.
\end{abstract}

Palavras-chave

Influências. Estudos Culturais. Brasil. Historiografia.

\begin{abstract}
This article seeks to present and discuss the English influences with the new discipline on cultural studies for Brazil, starting from the presupposition of its idealizers, the scholars Richard Hoggart, Raymond Williams and E. P. Thompson, with the goal of carrying out a historical and reflective analysis about the cultural dynamic and its correlations with the various areas human sciences, related with the existence and communal interaction of the human being, as a social being, within the colonization and civilization process. This new methodology was very important for
\end{abstract}

[Texto recebido em maio de 2018 e aceito em junho de 2018, com base na avaliação cega por pares realizada por pareceristas ad hoc]

* Graduado em História pela Universidade do Norte (2004). Especialista em História e Historiografia da Amazônia pela Universidade Federal do Amazonas (2006). Especialista em Educação para a Terceira Idade pela UNYLEYA (2013). Mestre em História e Estudos Culturais pela Universidade Federal de Rondônia (2016). Docente no Instituto Federal de Educação, Ciência e Tecnologia do Amazonas. E-mail: fabiolima18.2009@hotmail.com

** Licenciado em Ciências Sociais pela Universidade Federal do Rio Grande do Sul (2011). Bacharel (2007), Mestre (2009) e Doutor (2015) em Teologia pela Escola Superior de Teologia. Atualmente, realiza Estágio de Pós-Doutorado na Escola Superior de Teologia. Docente no Instituto Federal de Educação, Ciência e Tecnologia do Amazonas. E-mail: ez.teologo@gmail.com 
Brazil because of the valorization of the arguments of the classic authors of Brazilian historiography.

Keywords

Influences. Cultural Studies. Brazil. Historiography.

\section{Introdução}

Com início no final do ano de 1950 e da década de 1960 na Inglaterra, a disciplina dos estudos culturais teve uma influência marcante no modo de se observar a trajetória da colonização e da civilização pela historiografia brasileira. Isso ocorreu a partir de argumentos históricos, que buscam resgatar as tradições culturais oriundas da colonização até os dias atuais. Essa trajetória será trabalhada neste artigo, para percebemos como a Inglaterra com a nova metodologia e seus percussores - Richard Hoggart, Raymond Williams e E. P. Thompson - influenciou o modo de avaliar a trajetória da historiografia brasileira, a partir das leituras dos autores clássicos como Gilberto Freyre, Sérgio Buarque de Holanda, Caio Prado Júnior, Florestan Fernandes, Celso Furtado e outros, cujas discussões giravam em torno das mudanças culturais e sua trajetória na historiografia brasileira.

Avaliam-se as mudanças culturais ocorridas no Brasil, a partir das influências vindas da Inglaterra, com os precursores dos estudos culturais, sobre análise dos estudos culturais, envolvendo a globalização e a obrigatoriedade de termos um padrão de sociedade que acompanhe o mercado consumidor, dentro dos princípios de modernidade. O mercado consumidor, que precisa ser moldado dentro de padrões estrangeiros, acaba influenciando o mecanismo tradicional das nossas comemorações festivas que, para atrair os clientes, padroniza-se em normas internacionais. Isso exclui a originalidade das criações dos eventos culturais.

A valorização da cultura tradicional também é suporte de discussão, pois o Brasil miscigenado foi, desde sua colonização, importando trocas de favores culturais, em busca de desenvolvimento econômico, social, político, religioso e tecnológico. Atualmente, todos esses objetos de estudo ajudam na descentralização das organizações culturais, criadas para esse modelo de civilização incorporado no Brasil, trazido pela colonização portuguesa. Portanto, apresenta-se esse breve contexto histórico, buscando elucidar a problemática das nossas raízes culturais e a valorização de nossa cultura.

O objetivo principal é fazer uma análise da trajetória na formação da sociedade brasileira, com todas as mudanças sociais desde a colonização até os padrões de civilização vigentes atualmente. Esperamos contribuir com a relevância social sobre a discussão dos estudos culturais, iniciada na Inglaterra e que está sendo muito trabalhada nas universidades brasileiras, dentro dessa nova abordagem de valorização da cultura.

\section{A valorização cultural analisada pela disciplina dos Estudos Culturais no Brasil}


Para falarmos sobre os estudos culturais no Brasil, precisamos partir dos pressupostos, oriundos das influências Inglesas. A partir de 1950, através de autores como Richard Hoggart, Raymond Williams e E. P. Thompson, fundadores oficiais dos estudos culturais, houve a valorização da cultura, da política, da educação, da sociedade e dos hábitos, através das obras "As utilizações da cultura" (1957), "Cultura e sociedade" (1958) e "A formação da classe operária inglesa" (1963). De acordo com Cevasco, "os três considerados, não por acaso, os livros fundantes da nova disciplina". ${ }^{1}$ Esta nova temática favoreceu um novo campo de estudo de grupos étnicos, mulheres e outros, tornam-se critérios positivos. Torna-se a voz do outro na academia, contextualizando com outras ciências e absorvendo antropólogos ao campo dos estudos culturais.

Através dos trabalhos realizados por esses autores, podemos avaliar as influências que migraram para as abordagens sobre a cultura no Brasil, que inicia sua economia como um país agrário, de colonização portuguesa e que foi bastante miscigenado. Portanto, não podemos iniciar uma análise sobre estudos culturais no Brasil sem que antes passássemos pelos clássicos da historiografia brasileira. Pesquisando na perspectiva cultural, precisamos elucidar que teremos que nos reportar às bases teóricas, através dos autores que iniciaram essa nova metodologia, para estudar a cultura, e analisarmos suas origens em prol das conquistas, desenvolvimento e valorização.

Primeiro, precisamos saber o conceito de "cultura" pelo olhar de vários teóricos. Para Williams, "cultura é todo um sistema de vida, no seu aspecto material, intelectual e espiritual" . ${ }^{2}$ Já Burker defende que "a cultura, como hoje a chamamos, tem uma história" ${ }^{3}$ Analisando cultura no pós-modernismo, percebemos outra mudança ideológica:

Assim, na cultura pós-moderna, a própria "cultura" se tornou um produto, o mercado tornou-se seu próprio substituto, um produto exatamente igual a qualquer um dos itens que o constituem: o modernismo era, ainda que minimamente e de forma tendencial, uma crítica à mercadoria e um esforço de forçá-la a se autotranscender. ${ }^{4}$

Para valorizarmos ainda os discursos sobe a análise do conceito de cultura, apresentamos também a visão elaborada por Edward Said, para que possamos ter um melhor entendimento acerca do assunto:

"Cultura" segundo Said designa todas as práticas, como as artes de descrição, comunicação e representação, que tem relativa autonomia perante os campos econômico, social e político, e que freqüentemente

CEVASCO, M. E. Dez lições sobre Estudos Culturais. São Paulo: Boitempo Editorial, 2003. p. 13.

2 WILLIAMS, R. Uma tradição do século XIX. In: WILLIAMS, R. Cultura e Sociedade: 1780 - 1850. São Paulo: Companhia Editora Nacional, 1969. p. 58.

3 BURKE, P. Estruturas da cultura popular. In: BURKE, P. Cultura Popular na Idade Moderna: Europa, 1500 1800. São Paulo: Companhia das Letras, 1995. p. 5.

4 JAMESON, F. O pós-modernismo ou a lógica cultural do capitalismo tardio. São Paulo: Ática, 1989. p. 15. 
existem sob formas estéticas, sendo o prazer um de seus principais objetivos [...] inclui-se tanto o saber popular sobre partes distantes do mundo quanto o conhecimento especializado de disciplinas como a etnografia, a historiografia, a filologia, a sociologia e a história literária. ${ }^{5}$

Todos os conceitos ajudaram a esclarecer um entendimento que retrata a formação cultural da história do Brasil, calcada em suas raízes coloniais de domínio e controle do poder. Podemos pensar que todas esses abordagens sobre cultura nos remetem a valorizamos os estudos culturais, a partir das transformações oriundas da história tradicional ao mundo moderno, chegando na interligação da globalização com o período pós-moderno, apresentando uma valorosa análise histórica dessas transformações de valores, desde a chegada dos portugueses até os dias atuais:

No Brasil iniciaram os portugueses a colonização em larga escala dos trópicos por uma técnica econômica e por uma política social inteiramente nova: apenas esboçadas nas ilhas subtropicais do Atlântico. A primeira: a utilização e o desenvolvimento de riqueza vegetal pelo capital e pelo esforço do particular; a agricultura; a sesmaria; a grande lavoura escravocrata. A segunda: o aproveitamento da gente nativa, principalmente da mulher, não só como instrumento de trabalho, mas como elemento de formação da família. ${ }^{6}$

Nesses argumentos de Freyre, percebemos a contribuição do nativo na formação da sociedade brasileira. Podemos observar que os países da América Latina colonizados pelos espanhóis não utilizaram do mesmo mecanismo para o crescimento populacional e para o desenvolvimento as terras conquistadas, utilizando da força e domínio, através do extermínio das populações nativas: "Semelhante política foi bem diversa da de extermínio ou segregação seguida por largo tempo no México e no Peru pelos espanhóis, exploradores de minas, e sempre e desbragadamente na América do Norte pelos ingleses". 7

De acordo com Merquior, "o espanhol colonizou com alma de cruzado; o português limitou-se a ocupar com espírito de aventureiro". ${ }^{8}$ Existem muitos discursos em relação à colonização da América, portanto, percebemos que as culturas que estavam se desenvolvendo foram nas maiorias dizimadas, ou aculturadas, pelo colonizador. Retomando a análise efetuada por Freud, para quem a cobiça e do desejo de conquista e poder fazem do ser humano um defensor dos seus interesses particulares,

5 SAID, E. Cultura e imperialismo. São Paulo: Companhia das Letras, 1995. p. 11.

6 FREYRE, G. Características gerais da colonização portuguesa do Brasil: formação de uma sociedade agrária, escravocrata e híbrida. In: FREYRE, G. Casa-Grande e Senzala: formação da família brasileira sob o regime da economia patriarcal. Rio de Janeiro: Record, 1998. p. 71.

7 FREYRE, 1998, p. 71.

8 MERQUIOR, J. G. Situação do Brasil na Crise da Cultura. In: MERQUIOR, J. G. Saudades do Carnaval: introdução à crise da cultura brasileira. São Paulo: Forense, 1972. p. 224. 
[...] o homem é inteiramente bom e bem disposto para como seu próximo, mas a instituição da propriedade privada corrompeu-lhe a natureza. A propriedade da riqueza privada confere poder ao indivíduo e, com ele, a tentação de maltratar o próximo, ao passo que o homem excluído da posse está fadado a se rebelar hostilmente contra seu opressor. ${ }^{9}$

Todas as abordagens iniciais são para a conceituação de que, muito antes da disciplina sobre os estudos culturais ser oficializada no Brasil, ela já vinha sendo trabalhada desde o período da colonização, através de autores que desenvolviam a historiografia colonial. Entretanto, somente a partir do ano de 1998 a disciplina foi oficializada e reconhecida no Brasil, com o objetivo de estudar e valorizar os nossos traços culturais. Suas influências são oriundas da Inglaterra, mas precisamos observar as diferenças entre os dois países, uma vez que existem grandes distorções relacionadas à questão social e cultural entre Brasil e Inglaterra, como assinalado por Cevasco:

Outra maneira com que se pode dar desenvolvimento à nova disciplina no Brasil é por meio da busca de pontos de convergência substantivos entre a crítica cultural brasileira e os parâmetros dos estudos culturais, tais como se constituíram na Grã-Bretanha. Não se trata de um estudo de influências, mas de encontrar as semelhanças entre projetos e formações comparáveis. ${ }^{10}$

Conhecemos as particularidades de cada país, mas também temos a consciência da realidade de que as novas tendências da disciplina dos estudos culturais estão relacionadas ao modo de valorizar a cultura no Brasil, cuja influência se deu através de autores ingleses. Porém, não entendemos que o projeto cultural implantado em países europeus é responsável pelas transformações sociais e culturais do Brasil. Cevasco lança uma importante luz a este respeito:

A ideia não é olhar como um projeto cultural de um país central e exportador de ideias e modos é imitado, ou a mesma coisa ao contrário, recusada por ser estrangeiro, em um país periférico, mas pensar nos dois países em permanente relação. Essa relação é sem dúvida desigual, mas é determinada pelo mesmo sistema preponderante lá como cá. ${ }^{11}$

Percebemos logo essa diferença se compararmos o tratamento da classe operária inglesa com o da classe trabalhadora brasileira, analisando dois discursos diferentes, o primeiro voltado para o modo de tratamento do proletário brasileiro e, o segundo, voltado para o proletário inglês:

\footnotetext{
9 FREUD, Sigmund. O futuro de uma ilusão, o mal-estar na civilização e outros trabalhos. Rio de Janeiro: Imago, 1974. p. 29-30.

10 CEVASCO, 2003, p. 175.

11 CEVASCO, 2003, p. 175.
} 
O modo como um marxista da classe média vê as classes proletárias enfermas geralmente de um dos seguintes defeitos: compadecer-se do trabalhador atraiçoado e humilhado, cujas faltas ele encara como resultando, quase inteiramente, do sistema triturador que o controla; admirar o que nele considera como reminiscências do bom selvagem, fomentado a nostalgia desses tipos de arte "melhores que todos os outros", a arte folclórica rural ou a arte urbana genuinamente popular, e um entusiasmo especial por todos os vestígios das mesmas, que crê serem ainda hoje detectáveis. ${ }^{12}$

A forma de tratamento e o mundo do trabalho do proletariado inglês é diferente do brasileiro. "A classe proprietária se define pelas diferenças de bens, que determinam a situação dos membros" ${ }^{13} \mathrm{Na}$ Inglaterra, o proletariado era o trabalhador das indústrias; no Brasil, refere-se aos trabalhadores de baixo poder aquisitivo e que são desprovidos de ofícios. A maneira como a classe proletária é tratada nos remete à ideia de povo humilhado, humilde. Isso se torna generalizado à população menos favorecida de proletários, em virtude de trabalhos de baixa qualidade que escritos por autores que não aprofundaram pesquisas dessa natureza.

Para decidir quem seriam as classes proletárias com vista a este estudo, o problema era, a meu ver, o seguinte: publicações de massa, onde colhi a maior parte de minha documentação, afectam um campo muito mais vasto que o dos grupos do proletariado de que tenho um conhecimento imediato; na verdade, e porque tendem a ser publicações sem classe, afectam todas as classes da sociedade. ${ }^{14}$

Partindo desse pressuposto, percebemos que o modelo cultural de vida de cada classe depende de como buscar resultados positivos, não valorizando muitas das análises desenvolvidas, uma vez que muitos autores não prestam atenção nos aspectos culturais e no contexto social de cada classe. Como cada indivíduo pode mudar sua condição social, torna-se importante avaliar a dimensão cultural.

Hoggart critica substancialmente determinada tendência intelectual em tratar as classes operárias ora através de um sentimento compadecido (devido à exploração capitalista), ora por meio de certa nostalgia (marcas de reminiscências do bom selvagem). Para o autor, em ambas as atitudes reside um sentimento semiapiedado, semiprotetor. ${ }^{15}$

Em virtude da herança colonial, percebemos que a forma como o Brasil foi colonizado, através do abuso de poder e a forma de dominação, fez com que as

12 HOGGART, R. As utilizações da cultura. Lisboa: Presença, 1973. p. 19.

13 FAORO, Raymond. Os donos do poder. Rio de Janeiro: Globo, 2001. p. 243.

14 HOGGART, 1973, p. 22.

15 COSTA, J. H. Os estudos culturais em debate: um convite às obras de Richard Hoggart, Raymund Williams \& E. P. Thompson. Revista Acta Scientiarum, Maringá, v. 34, n. 2, p. 159-168, jul. 2012. p. 160. 
autoridades, responsáveis pelo desenvolvimento econômico, político e administrativo, herdassem o direito de achar que os cargos públicos fossem definidos como bem particular. A tese segundo a qual o brasileiro seria um "homem cordial" foi desenvolvida pelo historiador Sérgio Buarque de Holanda em seu livro já clássico Raízes do Brasil. O capítulo do livro que trata do assunto mostra que no Brasil não há uma distinção entre público e privado. O brasileiro costuma tratar o público como uma extensão de sua casa, de sua família. Daí surge a apropriação indevida de bens públicos, assim como a utilização da máquina burocrática estatal como cabide de emprego familiar:

Nenhum povo está mais distante dessa noção ritualista da vida do que o brasileiro. Nossa forma ordinária de convívio social é, no fundo, justamente o contrario da polidez. Ela pode iludir na aparência, e isso se explica pelo fato de atitude polida consistir precisamente em uma espécie de mímica deliberada de manifestações que são espontâneas no "homem cordial": é a forma natural e viva que se converteu em fórmula. Além disso, a polidez é, de algum modo, organização de defesa ante a sociedade. Detém-se na parte exterior, epidérmica do indivíduo, podendo mesmo servir, quando necessário, de peça de resistência. Equivale a um disfarce que permitirá a cada qual preservar intatas sua sensibilidade e suas emoções. ${ }^{16}$

A apesar das falsas ilusões, muitas vezes feitas em virtude de não querer criticar, ou avaliar trabalhos literários, ou mesmo falar seu ponto de vista sobre certos assuntos, a ideia de cordialidade dá um entendimento, que esse modelo permanece muito presente no Brasil, e precisamos romper as barreiras, como afirma João Cezar de Castro Rocha:

É preciso romper o círculo vicioso da cordialidade ao celebrar um livro por amizade. Se não mudarmos nossos hábitos, a vida acadêmica e os cadernos literários serão um mercado de falsas reputações, cuja moeda de troca é o elogio recíproco. Precisamos reinventar a vida intelectual, nada menos do que isso. ${ }^{17}$

Esse discurso sobre cordialidade, interesses pessoais, e o famoso "jeitinho brasileiro", em prol de benefícios próprios precisam ser rompidos, para que a sociedade seja mais bem valorizada e termos um olhar para todos sem diferenças sociais. As influências na colonização, juntamente com a população nativa que viviam no Brasil, apresentam trocas de hábitos culturais que valoriza a formação da sociedade brasileira através da miscigenação entres índios, negros e brancos, como é relatado nos estudos realizados de adaptações na colônia:

De modo que o homem já não é o antigo mané-gostoso de carne abrindo os braços ou deixando-os cair, ao aperto do calor ou do frio. Sua capacidade

16 HOLANDA, S. B. de. Raízes do Brasil. São Paulo: Companhia das Letras, 1995. p. 147.

17 ROCHA, J. C. de C. Literatura e cordialidade: o público e o privado na cultura brasileira. Rio de Janeiro: EdUERJ, 2003. p. 87. 
de trabalho, sua eficiência econômica, seu metabolismo alteram-se menos onde a higiene e a engenharia sanitária, a dieta, a adaptação do vestuário e da habitação às novas circunstâncias criam lhe condições de vida de acordo com o físico e a temperatura da região. ${ }^{18}$

Caio Prado Júnior analisa essa situação com outra visão cultural, em que prevalece a valorização do índio e do negro como mecanismo de colonização e o desenvolvimento populacional:

O negro e o índio teriam tido certamente outro papel na formação brasileira, e papel amplo e fecundo, se diverso tivesse sido o rumo dado à colonização; se se tivesse procurado neles, ou aceitado uma colaboração menos unilateral e mais larga que a do simples esforço físico. ${ }^{19}$

Ainda segundo Caio Prado Júnior, “a colonização brasileira se processa num plano acanhado" ${ }^{20}$ Esse modelo de colonização reflete no modelo de modernidade implantado pela colonização, ou seja, percebemos que o Brasil busca sempre copiar os modelos econômicos, sociais e culturais oriundos de outros países desenvolvidos, dando a impressão que estaremos sempre em sistema de colonização.

Nesse aspecto, sentimo-nos tentados a falar de algo novo e historicamente original: a penetração e colonização do Inconsciente e da Natureza, ou seja, a destruição da agricultura pré-capitalista do Terceiro Mundo pela Revolução Verde e a ascensão das mídias e da indústria da propaganda. ${ }^{21}$

Nesta situação, os países periféricos precisam se adaptar ao sistema de modernidade, conforme argumentado por Jameson, fazendo uma abordagem da indústria do consumo. Principalmente na forma como as manifestações culturais de massa precisam se adaptar ao modelo exigido pela mídia para atrair consumidores, desrespeitando as tradições originais. Para Ortiz, “a noção de modernidade está 'fora do lugar' na medida em que o Modernismo ocorre no Brasil sem modernização". 22 Já Salles Gomes remete ao fato de sempre imaginarmos que estamos importando cultura: “Não somos europeus nem americanos do norte, mas destituídos de cultura original, nada nos é estrangeiro, pois tudo o é. A penosa construção de nós mesmo se desenvolve na dialética rarefeita entre o não ser e o ser outro". 23

18 FREYRE, G. O sobrado e o mucambo. In: FREYRE, G. Sobrados e Mucambos: Introdução à história da sociedade patriarcal no Brasil. Rio de Janeiro: Record, 1998. p. 70.

19 PRADO JÚNIOR. Formação do Brasil contemporâneo. São Paulo: Brasiliense, 1994. p. 273.

20 PRADO JÚNIOR, 1994, p. 273.

21 JAMESON, 1989, p. 61.

22 ORTIZ, R. A moderna tradição brasileira. Cultura Brasileira e Indústria Cultural. São Paulo: Brasiliense, 1991. p. 32.

23 SALLES GOMES, P. E. Cinema: trajetória no subdesenvolvimento. São Paulo: Paz e Terra, 1986. p. 90. 
Essa ideia nos remete a fatos coloniais de imitações e importações de hábitos europeus, adaptados através de uma cultura colonial enraizada na nossa historiografia. Porém, para Said, "a história de todas as culturas é a história dos empréstimos culturais". ${ }^{24}$ A respeito dos padrões de consumo, podemos cita como exemplo: o Carnaval do Rio de Janeiro, Boi Bumbá de Parintins/AM, Ciranda de Manacapuru/AM, Festa do Guaraná em Maués/AM e muitas outras festividades regionais que precisaram se adaptar a padrões europeus, patrocinados por empresas com grandes investimentos, para atrair turistas estrangeiros. Há uma valorização do lucro e um desrespeito das tradições e da cultura do povo.

Somos uma sociedade de tradições coloniais que precisou se modificar para receber, investimentos comerciais, sendo necessário valorizar a capacitação e a intelectualidade para poder atender aos anseios do mercado europeu. "Considerando mero resíduo da sociedade colonial, a superpopulação excelente marginalizada do mercado de trabalho torna-se um problema desvinculado dos determinantes do desenvolvimento econômico". 25

Como podemos ter uma sociedade de consumo se não temos mão de obra qualificada para geração de emprego e renda? Seremos mão de obra barata e desqualificada para atendermos ao mercado consumidor internacional, ou apenas mera colônia de matéria prima. Para pensamos como a cultura é analisada em sociedades distintas como a nossa, temos que avaliar os trabalhos de Bosi, que defende:

Se pelo termo cultura entendemos uma herança de valores e objetos compartilhada por um grupo humano relativamente coeso, poderíamos falar em uma cultura erudita brasileira, centralizada no sistema educacional (e principalmente nas universidades), e uma cultura popular, basicamente iletrada, que corresponde aos mores materiais e simbólicos do homem rústico, sertanejo ou interiorano, e do homem pobre suburbano ainda não de todo assimilado pelas estruturas simbólicas da cidade moderna. ${ }^{26}$

A cultura tradicional criada nas ruas é levada às universidades, para ser conceituada. É cultura do povo, chamada popular. O Brasil é diversificado com as realizações festivas criadas pela população, por, a título de exemplo, o carnaval, as letras de samba, criadas nos morros, são utilizadas com mecanismo cultural da elite. Neste contexto, observamos que a cultura brasileira precisa ser mais bem valorizada, mas sua cultura dentro da originalidade, não descaracterizando as tradições em virtude dos ganhos comerciais. Como relata Latour, falando do respeito pela originalidade, "o sentimento de

24 SAID, 2011, p. 339.

25 SAMPAIO JÚNIOR, P. A. Entre nação e barbárie: os dilemas do capitalismo dependente em Caio Prado, Florestan Fernandes e Celso Furtado. Petrópolis: Vozes, 1999. p. 50.

26 BOSI, A. Plural, mas não caótico. In: BOSI, A. Cultura Brasileira: temas e situações. São Paulo: Ática, 2002. p. 309. 
originalidade que busca outra cultura não tem interesse senão para fazer refletir sobre a originalidade da sua própria, sem o que degenera em exotismo, em orientalismo". ${ }^{27}$ Respeitar o tradicional, o original e o popular, para valorizar as raízes de seus idealizadores, como critica Merquior:

Seria triste que o Brasil, sendo, por sua formação, depositário de paradigmas culturais que mal ou bem resistiram a algumas das mutilações humanas provocadas pela racionalização da vida, abdicasse dêsse passado no exato instante em que o futuro lhe confere tanto sentido. 28

Todos os textos pesquisados facilitaram o entendimento das nossas várias distinções sociais, pois o entendimento e compreensão das discussões valorizam o aprendizado, e os estudos culturais no Brasil precisando ser melhor valorizados, para que possamos compreender nossas raízes.

\section{Conclusão}

Os textos pesquisados são oriundos das aulas da disciplina de "Introdução aos Estudos Culturais", do mestrado em "História e Estudos Culturais", oferecido pela Universidade Federal de Rondônia-UNIR. Todos os textos foram apresentados em sala de aula na forma de Seminários, para que pudéssemos começar uma discussão sobre a origem e influência da nova disciplina sobre os estudos culturais oriundos da Inglaterra e seu início no Brasil.

O mais difícil de se trabalhar foi a gama de informações, que muitas vezes acabam passando pela a vida da gente despercebida. Quando começamos a trabalhar as leituras, percebemos as transformações que a cultura foi tendo durante as mudanças históricas, desde os nossos antepassados até os dias atuais. Quando falamos em valorizar os antepassados não queremos um resgate do passado, com o retorno do modo de vida, mas entender a origem, que foram ocorrendo ao longo da civilização, uma vez que, como definido por Freud, quando o homem conhece as facilidades da civilização, não quer voltar às origens:

[...] Os povos primitivos que ainda hoje existem, pesquisas cuidadosas mostraram que sua vida instintiva não é, de maneira alguma, passível de ser invejada por causa de sua liberdade. Está sujeita a restrições de outra espécie, talvez mais severas do que aquelas que dizem respeito ao homem moderno. ${ }^{29}$

Começamos a pensar que a nova disciplina dos estudos culturais ajuda a entender todas as possibilidades de conhecimento e valorização da cultura brasileira (sua herança, tradição, hábitos e conhecimento) tendo em vista que a modernização, o conhecimento e

27 LATOUR, B. Políticas da natureza: como fazer ciência na democracia. São Paulo/Bauru: Edusc, 2004. p. 85.

28 MERQUIOR, 1972, p. 243.

29 FREUD, 1974, p. 31. 
facilidade de valorização do espaço-tempo. A busca do desenvolvimento é para melhorar a condição social das pessoas, não através da cordialidade, mas das possibilidades de conhecimento cultural.

\section{Referências}

BOSI, A. Plural, mas não caótico. In: BOSI, A. Cultura Brasileira: temas e situações. São Paulo: Ática, 2002.

BURKE, P. Estruturas da cultura popular. In: BURKE, P. Cultura Popular na Idade Moderna: Europa, 1500 - 1800. São Paulo: Companhia das Letras, 1995.

CEVASCO, M. E. Dez lições sobre Estudos Culturais. São Paulo: Boitempo Editorial, 2003.

COSTA, J. H. Os estudos culturais em debate: um convite às obras de Richard Hoggart, Raymund Williams \& E. P. Thompson. Revista Acta Scientiarum, Maringá, v. 34, n. 2, p. 159168, jul. 2012.

FAORO, Raymond. Os donos do poder. Rio de Janeiro: Globo, 2001.

FREUD, Sigmund. O futuro de uma ilusão, o mal-estar na civilização e outros trabalhos. Rio de Janeiro: Imago, 1974.

FREYRE, G. Características gerais da colonização portuguesa do Brasil: formação de uma sociedade agrária, escravocrata e híbrida. In: FREYRE, G. Casa-Grande e Senzala: formação da família brasileira sob o regime da economia patriarcal. Rio de Janeiro: Record, 1998.

. O sobrado e o mucambo. In: FREYRE, G. Sobrados e Mucambos: Introdução à história da sociedade patriarcal no Brasil. Rio de Janeiro: Record, 1998.

HOGGART, R. As utilizações da cultura. Lisboa: Presença, 1973.

HOLANDA, S. B. de. Raízes do Brasil. São Paulo: Companhia das Letras, 1995.

JAMESON, F. O pós-modernismo ou a lógica cultural do capitalismo tardio. São Paulo: Ática, 1989.

LATOUR, Bruno. Politicas da natureza: como fazer ciência na democracia. São Paulo/Bauru: Edusc, 2004.

MERQUIOR, J. G. Situação do Brasil na Crise da Cultura. In: MERQUIOR, J. G. Saudades do Carnaval: introdução à crise da cultura brasileira. São Paulo: Forense, 1972.

ORTIZ, R. A moderna tradição brasileira. Cultura Brasileira e Indústria Cultural. São Paulo: Brasiliense, 1991.

PRADO JÚNIOR. Formação do Brasil contemporâneo. São Paulo: Brasiliense, 1994.

ROCHA, J. C. de C. Literatura e cordialidade: o público e o privado na cultura brasileira. Rio de Janeiro: EdUERJ, 2003. 
SAID, E. Cultura e imperialismo. São Paulo: Companhia das Letras, 1995.

SALLES GOMES, P. E. Cinema: trajetória no subdesenvolvimento. São Paulo: Paz e Terra, 1986.

SAMPAIO JÚNIOR, P. A. Entre nação e barbárie: os dilemas do capitalismo dependente em Caio Prado, Florestan Fernandes e Celso Furtado. Petrópolis: Vozes, 1999.

WILLIAMS, R. Uma tradição do século XIX. In: WILLIAMS, R. Cultura e Sociedade: 1780 1850. São Paulo: Companhia Editora Nacional, 1969. 